\title{
High-Performance Thin-Layer Chromatography Analysis of Gallic Acid and Other Phytoconstituents of Methanolic Extracts of Myrica nagi Fruit
}

\author{
Yash Prashar, Nilesh J. Patel ${ }^{1}$ \\ Ph.D Research Scholar, Ganpat University, Ganpat Vidyanagar, Mehsana-Gozaria Highway, 'Department of Pharmacology, Shree S.K. Patel College of Pharmaceutical \\ Education and Research, Ganpat University, Ganpat Vidyanagar, Mehsana-Gozaria Highway, Kherva, Gujarat, India
}

\begin{abstract}
Background: Myrica nagi Thunb. (family: Myricaceae) is effective against gastric, metabolic, and hepatic disorders. The therapeutic effect of its fruit, which is consumed in North India, has not been confirmed, and detailed chemical profiling of the fruit is thus required. Objectives: The study objective was to develop and optimize a high-performance thin-layer chromatography (HPTLC) method for the characterization of gallic acid, quercetin, myricetin, and caffeic acid in the methanolic extract of $M$. nagi fruit and the quantification of gallic acid. Materials and Methods: Analyses were performed using HPTLC, and liquid chromatography-mass spectrometry. HPTLC experiments were carried out using an optimized solvent mixture, which enabled the separation and detection (at 254 and $366 \mathrm{~nm}$ ) of four flavonoid compounds in the dried $M$. nagi extract. Gallic acid was quantified using calibration curves. Results: The proposed method enabled the detection of gallic acid, quercetin, myricetin, and caffeic acid. Validation took into account the estimation of linearity, limit of detection, limit of quantification, accuracy, and recovery of gallic acid. Gallic acid was quantified at $12.93 \mu \mathrm{g} / \mathrm{mg}$ of dry plant concentrate. Conclusion: This study describes the development of an HPTLC method for the analysis and characterization of phytoconstitutents in the methanolic solution of a dried $M$. nagi fruit extract. The method was successfully validated for the analysis of gallic acid.

Key words: Flavonoid, gallic acid, high-performance thin-layer chromatography, liquid chromatography-mass spectrometry, Myrica nagi

\section{SUMMARY}

We performed full chemical profiling of the fruit extract of Myrica nagi and provided insights into the various phytoconstituents present in the fruit through LC-MS. The presence of various phytocompounds was confirmed through HPTLC. The method for gallic acid analysis was validated in a solvent system of ethyl formate/toluene/formic acid/water 20:1:2.6:0.5 $(v / V / V / V)$. The method allowed excellent separation of the compounds and can be of high importance for further quantification of phytocompounds and for the development of herbal formulations.
\end{abstract}

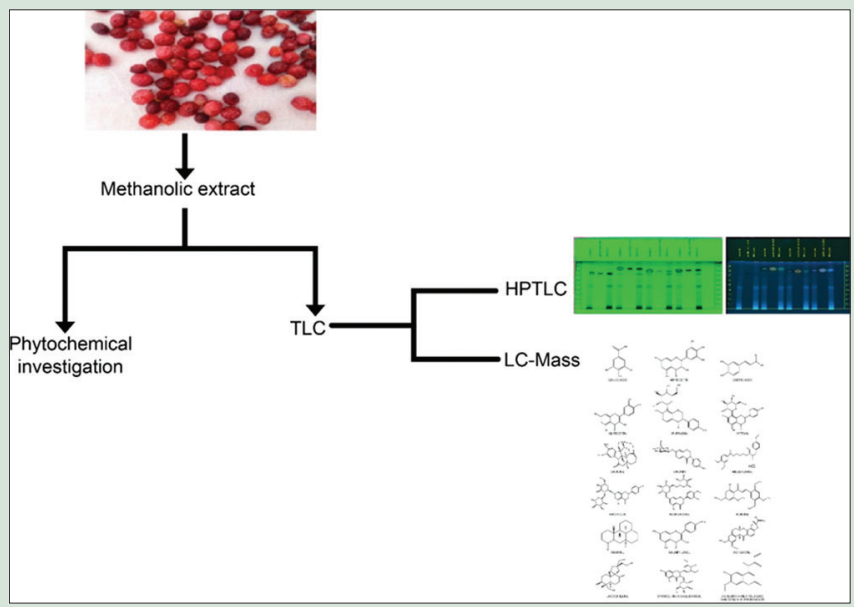

Abbreviations Used: HPLC: High-pressure liquid chromatography, HPTLC: High-performance thin-layer chromatography, ESI: Electrospray ionization, LC-MS: Liquid chromatography-mass spectrometry, LOD: Limit of detection, LOQ: Limit of quantification, MS: Mass spectrometry, Rf: Retention factor, TLC: Thin-layer chromatography.

Correspondence:

Dr. Nilesh J. Patel,

Department of Pharmacology, Shree S. K. Patel College of Pharmaceutical Education and Research, Ganpat University, Ganpat Vidyanagar, Mehsana-Gozaria Highway, Kherva, Gujarat - 384 012, India.

E-mail: nileshcology127@gmail.com; yashprashar@gmail.com DOI: 10.4103/pr.pr_104_19
Access this article online

Website: www.phcogres.com

Quick Response Code:

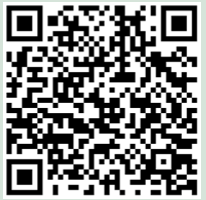

\section{INTRODUCTION}

Myrica nagi Thunb. (syn. Myrica esculenta), commonly known as box myrtle, katphala, boxberry, and orkaphal, belongs to the family Myricaceae and is a widely used medicinal plant. M. nagi is sourced primarily for its fruits, ${ }^{[1]}$ which are similar to raspberries and are deep red in color, with a small amount of pulp and a round seed at the center. The bark of this plant contains chemical compounds, such as myricetin, myricitrin, and specific glycosides. It has been reported to possess anti-allergic, ${ }^{[2]}$ anti-inflammatory, ${ }^{[3]}$ antioxidant, ${ }^{[4]}$ antihelminthic, ${ }^{[5]}$ antimicrobial, ${ }^{[6]}$ anxiolytic, ${ }^{[7]}$ chemoprotective, ${ }^{[8]}$ hypertensive, ${ }^{[9]}$ mast cell-stabilizing, ${ }^{[10]}$ analgesic, ${ }^{[11]}$ antiulcerating, ${ }^{[12]}$ antidiabetic, ${ }^{[13]}$ hepatoprotective, ${ }^{[14]}$ and wound-healing ${ }^{[15]}$ properties. This has led to the development of new therapeutic medicines using $M$. nagi extract. ${ }^{[16]}$

Analysis of herbal samples typically involves several steps, including sample preparation, separation, and detection. Sample preparation is

the first essential step and involves the extraction of analytes of interest. Modern, state-of-the-art sample preparation and separation methods offer substantial benefits over standard methods for the characterization of medicinal plants, playing an essential role in the commercialization of high-quality herbal products. ${ }^{[17]}$ Thin-layer chromatography (TLC) is a simple and cost-effective separation technique enabling the analysis

This is an open access journal, and articles are distributed under the terms of the Creative Commons Attribution-NonCommercial-ShareAlike 4.0 License, which allows others to remix, tweak, and build upon the work non-commercially, as long as appropriate credit is given and the new creations are licensed under the identical terms.

For reprints contact: reprints@medknow.com

Cite this article as: Prashar Y, Patel NJ. High-performance thin-layer chromatography analysis of gallic acid and other phytoconstituents of methanolic extracts of Myrica nagi fruit. Phcog Res 2020;12:95-101. 
of several samples simultaneously; hence, it is often considered the first option for diverse medicinal analytical applications. High-pressure liquid chromatography (HPLC) and high-performance thin-layer chromatography (HPTLC) are widely employed to characterize and analyze numerous bioactive mixtures, enabling the detection of constituents, including secondary metabolites, nutrients, and amino acids. ${ }^{[18]}$ Hence, HPTLC represents an attractive technique for qualitative and quantitative analyses of herbal extracts. ${ }^{[19]}$ Mass spectrometry (MS) provides highly accurate structural information about the constituents of herbal extracts, allowing the identification of compounds of interest. Overall, an effective, high-throughput screening and separation technique combined with MS detection is crucial for the identification of potential natural therapeutic candidates. ${ }^{[20]}$

This study aimed to develop and validate a high-throughput HPTLC method for the characterization of gallic acid, quercetin, myricetin, and caffeic acid in methanolic extracts of the M. nagi fruit. The developed method was validated for gallic acid.

\section{MATERIALS AND METHODS}

\section{Chemicals}

All solvents, including methanol, butanol, acetic acid, formic acid, and toluene, were of analytical grade and purchased from SD Fine Chemicals (Mumbai, Maharashtra, India). Flavonoid standards, such as those for gallic acid, quercetin, myricetin, and caffeic acid, were purchased from Natural Remedies (Bengaluru, Karnataka, India).

\section{Collection of Myrica nagi}

Fruit samples of $M$. nagi were collected from Mandi district, Himachal Pradesh, India, in July 2017. The collected plant material was authenticated by NISCAIR, Delhi, India (Ref. No. NISCAIR/RHMD/ Consult//2017/3102-51-4). Healthy fruits were separated and kept for further analyses.

\section{Methanolic extraction of Myrica nagi fruits}

Freshly collected $M$. nagi fruits were dried in the shade and milled into a coarse powder. Then, $500 \mathrm{~g}$ of the finely powdered sample was subjected to a 4 -h extraction with methanol at $55^{\circ} \mathrm{C}-65^{\circ} \mathrm{C}$ using a Soxhlet device (Buchi, Mumbai, Maharashtra, India). Before and after each extraction, the organic extract was accurately weighed, dried, and passed through a filter paper of $120 \mathrm{~mm}$ diameter and medium porosity (S and S., Dassel, Germany). This extraction step was repeated thrice, and the extract was eventually dried using a rotary evaporator (Rotavapor Heizdab WB eco, Heidolph Instruments, Schwabach, Germany). The dried extracts were combined prior to further analyses.

\section{Preliminary phytochemical investigation}

The extract was subjected to phytochemical screening following standard methods. ${ }^{[21,22]}$

\section{Preparation of sample and standard solutions}

Standard stock solutions of $1 \mathrm{mg} / \mathrm{mL}$ were prepared by dissolving the standards in methanol. Standard stock solutions were further diluted in methanol to obtain a working solution of $25 \mu \mathrm{g} / \mathrm{mL}$. An appropriate amount of weighed methanolic extract was dissolved in methanol to obtain a $10 \mathrm{mg} / \mathrm{mL}$ sample solution.

\section{High-performance thin-layer chromatography analysis}

Precoated silica gel $60 \mathrm{~F}_{254}$ TLC plates were first washed with methanol. The silica was activated by placing the plates in an oven at $60^{\circ} \mathrm{C}$ for
$15 \mathrm{~min}$. The solutions were applied to the plates using an automatic TLC sampler (CAMAG ${ }^{\circ}$ ATS; CAMAG, Muttenz, Switzerland) equipped with a $100-\mu \mathrm{L}$ syringe at a steady implementation rate of $150 \mathrm{~nL} / \mathrm{s}$. The solutions were applied onto prewashed TLC plates in 5-mm broad bands, $10 \mathrm{~mm}$ from the bottom edge, $10 \mathrm{~mm}$ from the side and top edges, and with $6 \mathrm{~mm}$ gaps between each spot. The CAMAG ${ }^{\circ}$ Twin Trough Chamber was presaturated for $20 \mathrm{~min}$ at $25^{\circ} \mathrm{C} \pm 2^{\circ} \mathrm{C}$ and $40 \%$ relative humidity, with the mobile phase composed of a mixture of ethyl formate/toluene/ formic acid/water 20:1:2.6:0.5 (v/v/v/v). ${ }^{[23-25]}$ The chromatographic run was approximately $80 \mathrm{~mm}$. After separation, the TLC plates were dried using an air current. Densitometric visualization of the chromatographic spot was performed at $254 \mathrm{~nm}$ and $366 \mathrm{~nm}$ using deuterium and mercury lamps in the CAMAG ${ }^{\circ}$ HPTLC instrument equipped with visionCATS software (CAMAG, Muttenz, Switzerland).

\section{Characterization of methanolic extracts using liquid chromatography-mass spectrometry}

The methanolic extract was analyzed using the 2795 Alliance HPLC system (Waters, Milford, MA, USA) coupled with a Micromass Q-TOF Micro Mass Spectrometer (Waters, Milford, MA, USA). Separation was carried out on an XBridge $C_{18}$ column $(130 \AA$, $3.5 \mu \mathrm{m}$, $4.6 \mathrm{~mm} \times 150 \mathrm{~mm}$; Waters). The mobile phase was composed of $80 \%$ methanol and $20 \%$ water and run in the isocratic mode. The flow rate was set at $0.7 \mathrm{~mL} / \mathrm{min}$. The injection volume was $20 \mu \mathrm{L}$. MS acquisition was performed using the electrospray ionization (ESI)-positive mode and multiple reaction monitoring with unit resolution. Desolvation gas and cone gas flow rates were set to $550 \mathrm{~L} / \mathrm{h}$ and $30 \mathrm{~L} / \mathrm{h}$, respectively. Desolvation gas and source temperatures were set to $300^{\circ} \mathrm{C}$ and $110^{\circ} \mathrm{C}$, respectively. The ESI capillary voltage was fixed at $3000 \mathrm{~V}$, and the cone voltage was set at $30 \mathrm{~V}$. Compounds were fragmented using collision energy of $4 \mathrm{eV}$. Nitrogen and argon were used at pressures of 6-7 bars and $5-6$ bars, respectively.

\section{Validation of the developed high-performance thin-layer chromatography method}

The developed HPTLC method was validated for the quantification of gallic acid in terms of specificity, precision, accuracy, limit of detection (LOD), and limit of quantification (LOQ) following the ICH guidelines. ${ }^{[26,27]}$

\section{Precision}

Intra- and inter-day precision was evaluated using a standard solution of gallic acid at $100 \mathrm{ng} / \mathrm{spot}$. Solutions were injected 12 consecutive times (intraday precision) on 2 consecutive days (interday precision). The results were evaluated using retention factor (Rf), peak area, and standard deviation.

\section{Limit of detection and limit of quantification}

The LOD and LOQ were calculated using the gallic acid calibration curve. Different volumes of gallic acid solution (1.0, 1.0, 2.0, 3.0, 4.0, 5.0, 6.0 , and $7.0 \mu \mathrm{L}$ ) were applied to the plate, together with different volumes of the methanolic extract $(2.0,2.0,3.0,3.0,4.0$, and $4.0 \mu \mathrm{L})$.

\section{Accuracy}

Accuracy reflects the positive and negative influences of other components present in the mixture on the quantification. The standard addition method was used to determine the accuracy of the developed protocol by calculating recoveries. Known and varying amounts of gallic acid were added at three different concentrations $(80 \%, 100 \%$, and $120 \%)$ of a predetermined amount. The average recovery and total recovery of gallic acid were calculated and expressed in percentages. 


\section{Specificity}

The specificity of the developed method was evaluated by measuring standard solutions, blank samples, and test samples. The spot of gallic acid obtained from the analysis of test samples was confirmed by comparing the $\mathrm{R}_{\mathrm{f}}$ values and spectra of the standard solutions. The purity of gallic acid was evaluated by observing the spectral peak's start, apex, and end for the spot.

\section{RESULTS}

This study aimed to identify flavonoids, gallic acid, quercetin, myricetin, and caffeic acid in methanolic extracts of the M. nagi fruit using HPTLC. These flavonoids have been shown to be among the active components of other herbal extracts. HPTLC was used for the qualitative and quantitative analyses of gallic acid.

\section{Extraction yield and phytochemical analysis}

Five hundred grams of the powdered fruit yielded $8.83 \mathrm{~g}$ of extract. The extract was a semi-solid, dark-brown mass with a characteristic odor. It was positive for the presence of alkaloids, glycosides, flavonoids, steroids, amino acids, carbohydrates, tannins, and phenols.

\section{High Performance Thin-layer chromatography analysis of Myrica nagi extract}

Table 1 presents the results of HPTLC analysis of the methanolic extract. Separation of the extract into single components is shown in Figures 1 and 2. The extract produced identical spots to those obtained for the standard samples. Gallic acid, was further quantified and new method was validated.

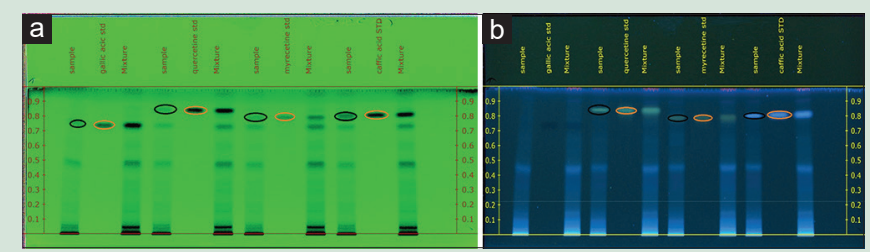

Figure 1: High Performance Thinlayer chromatography obtained for the methanolic extract and standard solutions of gallic acid, quercetin, myricetin, and caffeic acid with ultraviolet detection at (a) $254 \mathrm{~nm}$ (left) and (b) $366 \mathrm{~nm}$ (right)

\section{Liquid chromatography-mass spectrometry analysis of Myrica nagi extracts}

The LC-MS analysis of the methanolic extract revealed 23 compounds, of which 18 were confirmed using the European MassBank database. The identified compounds included gallic acid, myricetin, caffeic acid, quercetin, puerarin, vitexin, brucine, mebeverine, ononin, rhoifolin, hesperidin, matrine, rotenone, rubone, syringetin-3-O-galactoside, lagochilline, 7-chloro-4-methyl-2-oxochromen-6-yl propanoate, and kaempferide. The structures of these compounds are presented in Figure 3. The obtained mass spectrum is shown in Figure 4. Table 2 lists the detected compounds.

\section{Validation of the newly developed high-performance thin-layer} chromatography method for the quantification of gallic acid

The method was validated and assessed for precision, accuracy, specificity, LOD, and LOQ using ICH guidelines. ${ }^{[26]}$

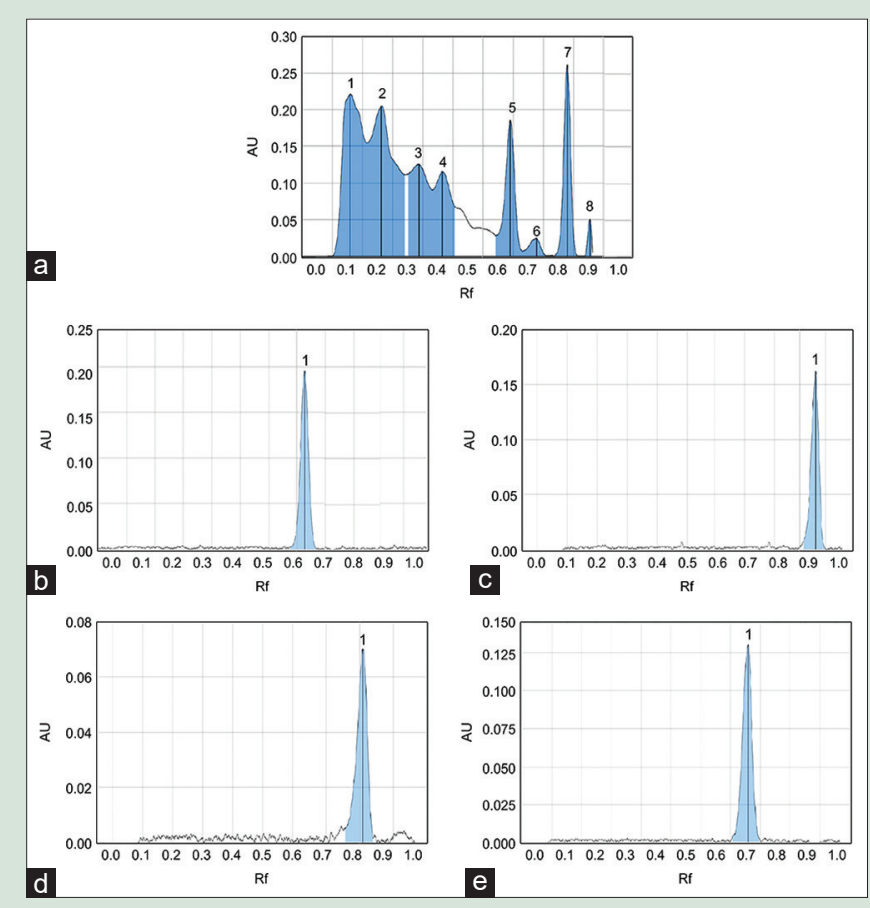

Figure 2: High-performance thin-layer chromatography obtained for (a) sample extract and standard solutions of (b) gallic acid; (c) quercetin; (d) myricetin; and (e) caffeic acid

Table 1: Retention factors of the different peaks observed in the methanolic extract of Myrica nagi by high-performance thin-layer chromatography analysis

\begin{tabular}{|c|c|c|c|c|c|c|c|c|c|c|}
\hline \multirow[t]{2}{*}{ Peak } & \multicolumn{2}{|c|}{ Start } & \multicolumn{3}{|c|}{ Maximum } & \multicolumn{2}{|c|}{ End } & \multirow[t]{2}{*}{ Area (\%) } & \multirow{2}{*}{$\begin{array}{c}\text { Manual } \\
\text { peak }\end{array}$} & \multirow[t]{2}{*}{ Substance } \\
\hline & RF & Height & RF & Height & Percentage & RF & Height & & & \\
\hline 1 & 0.100 & 0.0000 & 0.159 & 0.2210 & 18.62 & 0.216 & 0.1538 & $0.01757(25.35)$ & No & Unknown \\
\hline 2 & 0216 & 0.1538 & 0.262 & 0.2047 & 17.25 & 0.342 & 0.1109 & $0.01952(28.17)$ & No & Unknown \\
\hline 3 & 0.350 & 0.1116 & 0.388 & 0.1250 & 10.53 & 0.430 & 0.0900 & $0.00906(13.08)$ & No & Unknown \\
\hline 4 & 0.430 & 0.0900 & 0.465 & 0.1150 & 9.69 & 0.506 & 0.0670 & $0.00738(10.65)$ & No & Unknown \\
\hline 5 & 0.642 & 0.0276 & 0.690 & 0.1855 & 30.63 & 0.731 & 0.0062 & $0.00707(30.20)$ & No & Gallic acid \\
\hline 6 & 0.731 & 0.0062 & 0.778 & 0.0240 & 25.02 & 0.810 & 0.0004 & $0.00105(25.52)$ & No & Quercetin \\
\hline 7 & 0.833 & 0.0000 & 0.879 & 0.2615 & 22.03 & 0.914 & 0.0000 & $0.00694(22.02)$ & No & Myricetin \\
\hline 8 & 0.938 & 0.0000 & 0.955 & 0.0501 & 20.22 & 0.963 & 0.0048 & $0.00071(20.02)$ & No & Caffeic acid \\
\hline 9 & 0.706 & 0.0032 & 0.757 & 0.1302 & 100 & 0.795 & 0.0028 & $0.00491(100)$ & No & Gallic acid standard \\
\hline 10 & 0.811 & 0.0069 & 0.860 & 0.1628 & 100 & 0.896 & 0.0013 & $0.00557(100)$ & No & Quercetin standard \\
\hline 11 & 0.758 & 0.0051 & 0.809 & 0.0703 & 100 & 0.840 & 0.0016 & $0.00261(100)$ & No & Myricetin standard \\
\hline 12 & 0.776 & 0.0022 & 0.827 & 0.1960 & 100 & 0.870 & 0.0003 & $0.00666(100)$ & No & Caffeic acid standard \\
\hline
\end{tabular}

RF: Retention factor 


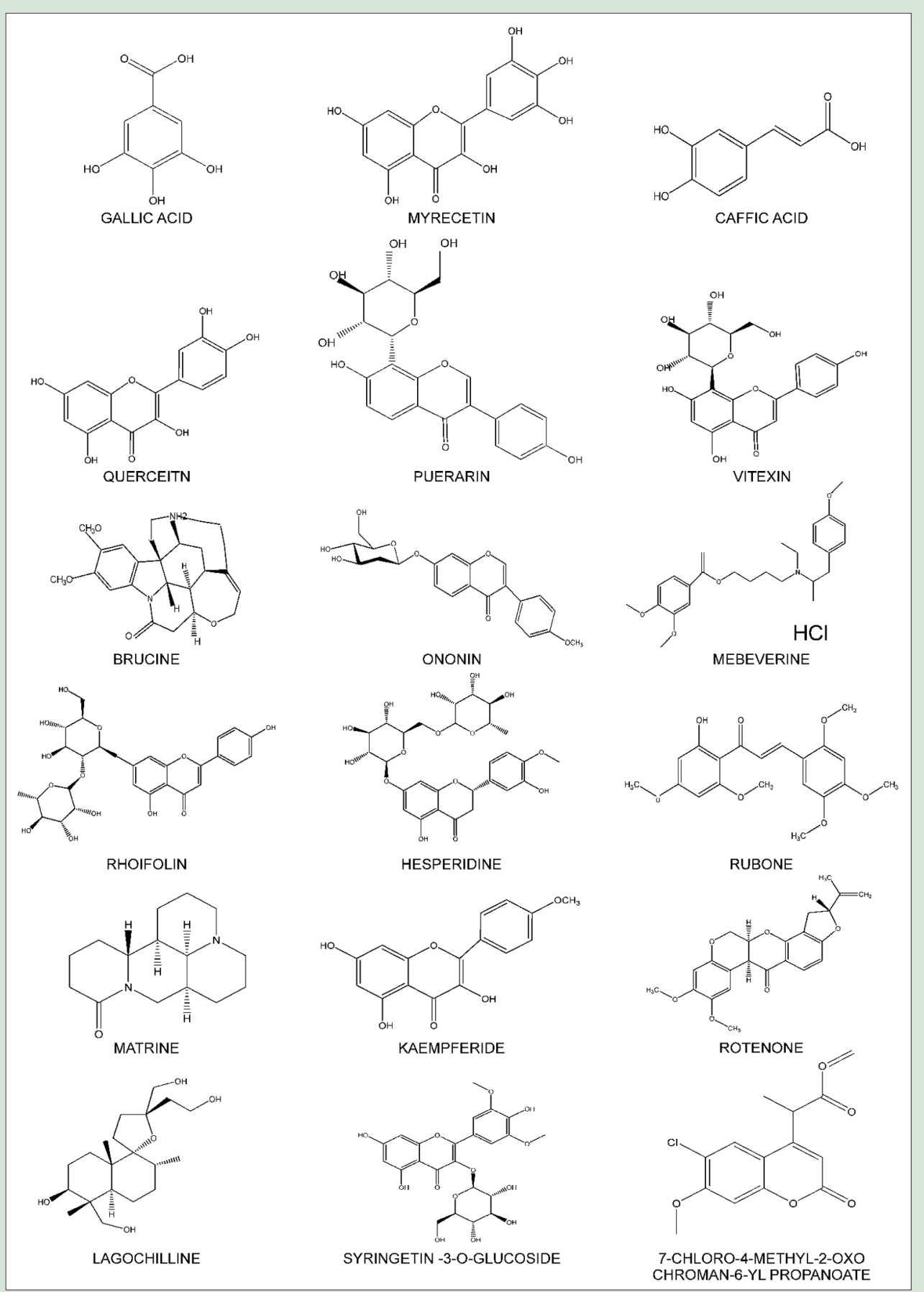

Figure 3: Structure of different compounds detected in Myrica nagi fruit extract by liquid chromatography-mass spectrometry

Figure 5 shows the results of precision evaluation, including intra- and inter-day repeatability. Figure 6 and Table 3 show the results of LOD and LOQ estimation. The evaluation of accuracy and recovery is shown in Figure 7 and Tables 4 and 5. Finally, specificity evaluation results are shown in Figure 8; they clearly demonstrated that bands were not observed in the mobile phase or in the solvent.

Table 6 presents a summary of the results for the various parameters evaluated during method validation. Linearity ranged from 100 to $700 \mu \mathrm{g} / \mathrm{spot}$, using a regression equation of $y=1.636 \times 10^{-8} \times$ $-1.904 \times 10^{-4}$. The accuracy/recovery of gallic acid was $90 \%-110 \%$.
Furthermore, this method exhibited a high precision, with a coefficient of variation of $1.65 \%$, which was comfortably below the $3 \%$ tolerance limit. The LOD was $38.3 \mathrm{ng}$ and the LOQ was $116.1 \mathrm{ng}$. The proposed method was determined to be highly specific due to the absence of bands in the mobile phase and solvent front. The method was finally employed to quantify the amount of gallic acid present in the methanolic extract, which was determined to be $129.3 \mu \mathrm{g} / 10 \mathrm{mg}$ of dry plant extract.

\section{DISCUSSION}

In this study, we first evaluated the phytochemical parameters of 
Table 2: List of compounds detected in the methanolic extract of Myrica nagi by liquid chromatography-mass spectrometry and identified based on data from the European MassBank database

\begin{tabular}{|c|c|c|c|c|c|c|c|}
\hline Peak number & RT & Peak height & Peak area & Area (\%) & $m / z$ & Compounds & Reference \\
\hline 1 & 0.48 & 10900 & 5453.11 & 2.77 & 113 & Unknown & European MassBank \\
\hline 2 & 0.97 & 1599 & 7050.40 & 3.59 & 114 & Unknown & European MassBank \\
\hline 3 & 2.40 & 16111 & 12757.56 & 20.49 & 170 & Gallic acid & European MassBank \\
\hline 4 & 2.57 & 14768 & 4902.14 & 2.49 & 266 & $\begin{array}{l}\text { 7-chloro-4-methyl-2-oxochromen-6-yl } \\
\text { propanoate }\end{array}$ & European MassBank \\
\hline 5 & 3.13 & 7126 & 1391.96 & 20.71 & 180 & Caffeic acid & European MassBank \\
\hline 6 & 3.60 & 7766 & 3003.83 & 1.53 & 248 & Matrine & European MassBank, PubChem \\
\hline 7 & 4.20 & 6757 & 4018.11 & 2.04 & 356 & Lagochilline & European MassBank \\
\hline 8 & 7.57 & 9315 & 5901.00 & 30.00 & $\begin{array}{l}301 \\
302 \\
318\end{array}$ & Quercetin, myricetin & European MassBank \\
\hline 9 & 8.37 & 10825 & 6278.49 & 3.19 & 363 & Unknown & European MassBank, NIST \\
\hline 10 & 8.82 & 10268 & 3740.68 & 1.90 & 432 & Vitexin & European MassBank \\
\hline 11 & 9.10 & 7495 & 1267.57 & 0.64 & $\begin{array}{l}394 \\
394\end{array}$ & Brucine, rotenone & European MassBank, PubChem \\
\hline 12 & 9.62 & 12354 & 3492.32 & 1.78 & 374.4 & Rubone & European MassBank \\
\hline 13 & 10.58 & 104809 & 63657.38 & 32.38 & $\begin{array}{l}416.3 \\
429.6\end{array}$ & Puerarin, mebeverine & European MassBank \\
\hline 14 & 14.32 & 4678 & 2315.99 & 1.18 & $\begin{array}{l}300 \\
430\end{array}$ & Kaempferide, ononin & European MassBank \\
\hline 15 & 22.95 & 5551 & 2091.33 & 1.06 & 610.5 & Hesperidin & European MassBank \\
\hline 16 & 23.85 & 2595 & 687.74 & 0.35 & 508 & Unknown & European MassBank \\
\hline 17 & 25.08 & 2352 & 703.16 & 0.36 & 509 & Syringetin-3-O-galactoside & European MassBank \\
\hline 18 & 26.93 & 0 & 2691.22 & 1.37 & 515 & Unknown & European MassBank \\
\hline 19 & 27.73 & 13111 & 3912.74 & 1.99 & 551 & Unknown & European MassBank \\
\hline 20 & 28.28 & 83122 & 37248.86 & 18.95 & 578.52 & Rhoifolin & European MassBank \\
\hline 21 & 31.07 & 20358 & 12272.02 & 6.24 & 644 & Unknown & European MassBank \\
\hline 22 & 31.23 & 18942 & 5375.77 & 2.73 & 645 & Unknown & European MassBank \\
\hline 23 & 31.60 & 13779 & 6369.86 & 3.24 & 693 & Unknown & European MassBank \\
\hline
\end{tabular}

RT: Retention time

Table 3: Limit of detection and limit of quantification for gallic acid

\begin{tabular}{lcccc}
\hline $\begin{array}{l}\text { Concentration } \\
(\mu \mathrm{g} / \mathrm{mL})\end{array}$ & Area & SD & LOD $(\mathrm{ng})$ & LOQ (ng) \\
\hline 100 & 0.001462 & 0.00019 & 38.3 & 116.1 \\
200 & 0.003085 & & & \\
500 & 0.007783 & & & \\
600 & 0.009924 & & & \\
700 & 0.011149 & & & \\
\hline
\end{tabular}

UV detection was carried out at $254 \mathrm{~nm}$. LOD: Limit of detection; LOQ: Limit of quantification; SD: Standard deviation; UV: Ultraviolet

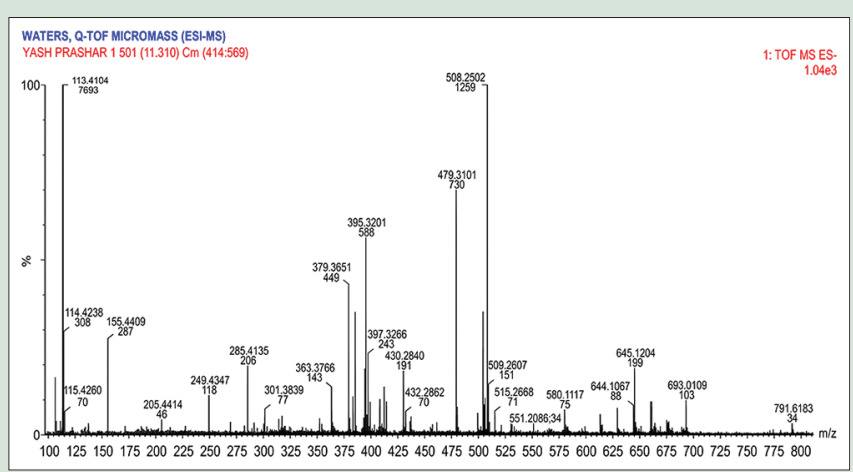

Figure 4: Mass spectrum of Myrica nagi fruit extract

a methanolic extract of the M. nagi fruit using HPTLC analysis. Because the antioxidant potential of $M$. nagi is influenced by its polyphenolic content, ${ }^{[28]}$ it is essential to investigate the bioactivity of each detectable polyphenolic compound present in the fruit of $M$. nagi. The use of flavonoids as therapeutics against various diseases has gained momentum in recent years. ${ }^{[29]}$ Phytoconstituents of $M$. nagi identified previously through LC-MS and HPTLC analyses have been demonstrated to act against tumors, asthma, chronic bronchitis, and several digestive and endocrine disorders. ${ }^{[30]}$ The newly developed HPTLC method enabled the analysis and quantification of gallic acid, a potential antioxidant ${ }^{[31]}$ present in this plant. Previous HPTLC studies performed on other plants had reported an $\mathrm{R}_{\mathrm{f}}$ value of 0.57 for gallic acid, ${ }^{[32]}$ which corresponds to the value obtained here. M. nagi grows in forests and is used by the local Himalayans (Uttarakhand and Himachal Pradesh). Gallic acid, which is known for its potent antioxidant activity, has not been detected before in the fruit of this species. By quantifying gallic acid and confirming the presence of various phytocompounds in the $M$. nagi extract via HPTLC and LC-MS, our study offers new information aimed at the use of this plant for therapeutic purposes and even industrial applications. Several studies have described the development of HPTLC methods for the quantification of compounds such as myricetin in the stem bark of M. esculenta. ${ }^{[28]}$ Our method is advantageous as it enables the future quantification of several other identified compounds, such as quercetin, myricetin, and caffeic acid. The reported $\mathrm{R}_{\mathrm{f}}$ values for quercetin (0.98), myricetin $(0.53),{ }^{[28]}$ and caffeic acid $(0.78)^{[32]}$ are identical to the ones obtained in our study. This newly developed strategy will prove essential for the standardization of methods associated with identifying and quantifying compound in extracts from this plant, many of which are used in various polyherbal formulations. HPTLC is a common method for characterizing complex herbal mixtures due to its elevated resolution of phytochemicals, which allows for precise and accurate quantitative analysis. ${ }^{[33]}$ 
Table 4: Recovery of gallic acid

\begin{tabular}{lcccc}
\hline Sample & $\begin{array}{c}\text { Mass of gallic acid present } \\
\text { in the sample }(\mathbf{n g})\end{array}$ & $\begin{array}{c}\text { Mass of gallic } \\
\text { acid }(\mathbf{n g})\end{array}$ & $\begin{array}{c}\text { Total calculated mass } \\
\text { of gallic acid }(\mathbf{n g})\end{array}$ & $\begin{array}{c}\text { Detected mass } \\
\text { of gallic acid (ng) }\end{array}$ \\
\hline 1 & 170.16 & 90.75 & 260.91 & 272 \\
2 & 170.16 & 113.44 & 283.6 & 286 \\
3 & 170.16 & 136.12 & 306.28 & 104.8 \\
\hline
\end{tabular}

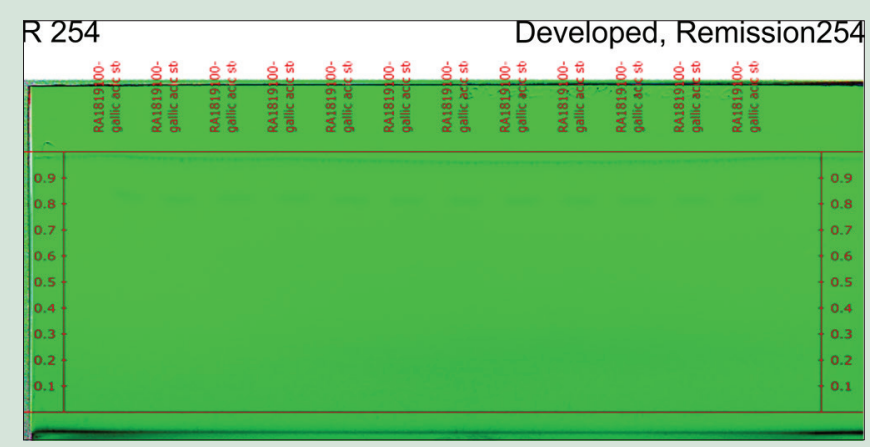

Figure 5: High Performance Thinlayer chromatography plate for precision (i.e., intraand interday variabilities). Ultraviolet detection performed at $254 \mathrm{~nm}$

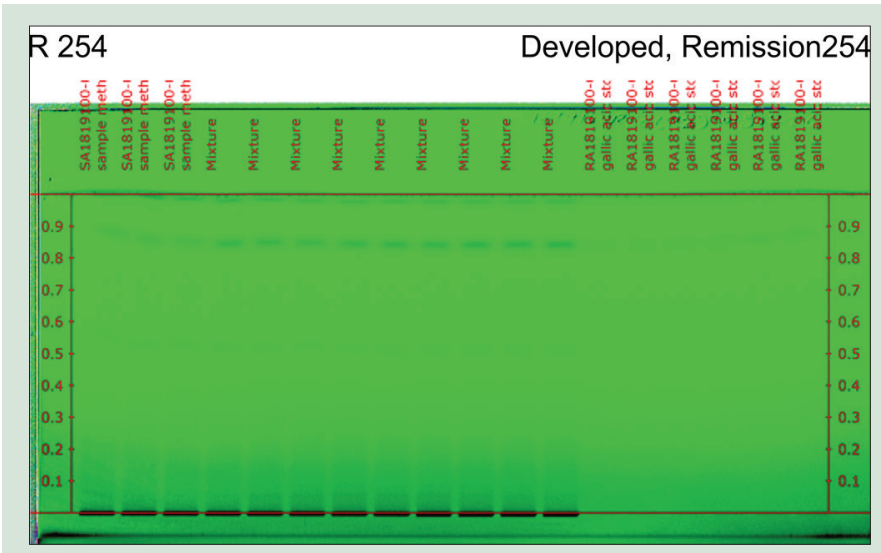

Figure 7: High Performance Thinlayer chromatography plate for accuracy. Ultraviolet detection carried out at $254 \mathrm{~nm}$

In this study, the HPTLC method was optimized to obtain a characteristic profile of the M. nagi fruit. The selected mobile phase provided comparable Rf values to standard compounds, demonstrating sufficient resolution and specificity by applying a single and fast run. With very high concentrations and using UV detection at $254 \mathrm{~nm}$, eight compounds were detected in the fruit extract. Furthermore, various experimental factors associated with this protocol, such as sample volume and LOD, had to be optimized. For example, the optimized sample volume was found to be $3 \mu \mathrm{L}$, which provided reproducible and accurate profiling, as well as information related to the number of compounds present in the extract, while facilitating the equilibrium between the various categories of phytocompounds present in the extract.

\section{CONCLUSION}

The developed and validated HPTLC method represents an effective technique for the quantification of gallic acid in a methanolic solution of $M$. nagi extract. The obtained results show that the

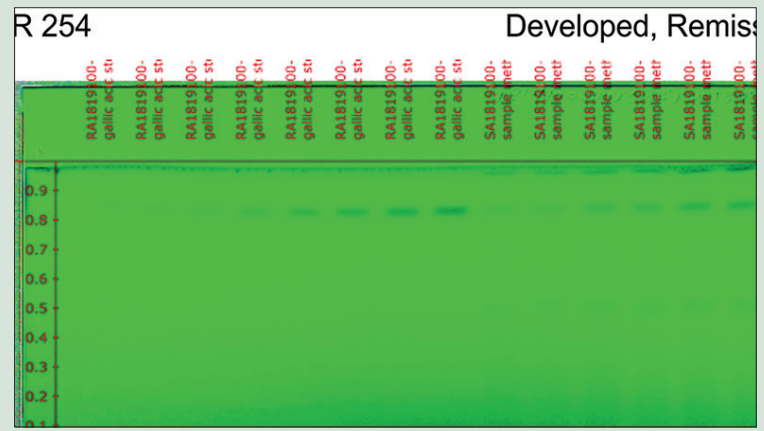

Figure 6: High Performance Thinlayer chromatography plate for limit of detection and limit of quantification. Ultraviolet detection carried out at $254 \mathrm{~nm}$

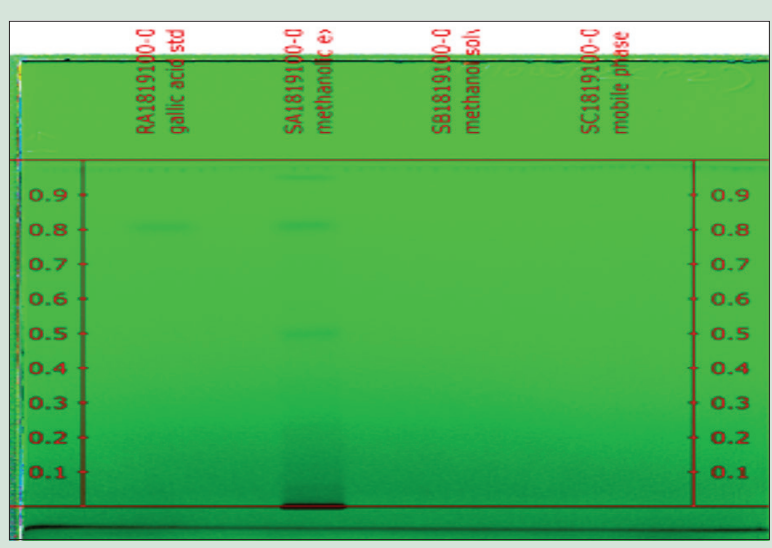

Figure 8: High Performance Thinlayer chromatography plate for specificity. Ultraviolet detection carried out at $254 \mathrm{~nm}$

methanolic extract of $M$. nagi contains various active compounds that may account for its therapeutic properties. Specifically, this study highlights the important therapeutic phytoconstituents of the fruit of $M$. nagi, which have been neglected by previous investigations. Due to the short shelf life of the fruit, the phytoconstituents contained in it need to be extracted as soon as the fruit ripens, for maximum benefit. Our study also suggests the use of $M$. nagi in herbal formulations for conditions related to stomach and endocrine disorders as the phytoconstituents identified here have been reported to confer such benefits. Furthermore, the proposed HPTLC method proved to be specific, accurate, and precise and was characterized by a high recovery rate. Additional phytoconstituents of the methanolic extract of $M$. nagi are currently under evaluation.

\section{Acknowledgements}

We thank Anchrom Enterprises, Mumbai, and SAIF/CIL, Punjab University, Chandigarh, for sample analysis. 
Table 5: Accuracy of gallic acid recovery values

\begin{tabular}{lcc}
\hline Expected value & Percentage & Mean (\%) \\
\hline 0.009667869 & 104.8 & \\
0.01039752 & 101.3 & 105.2 \\
0.009975397 & 109.5 & \\
\hline
\end{tabular}

Table 6: Summary of the validation parameters estimated using the developed high-performance thin-layer chromatography method

\begin{tabular}{lc}
\hline Parameter & Results \\
\hline Linearity (quantification) & $100-700 \mu \mathrm{g} /$ spot \\
Linear regression equation & $y=1.636 \times 10^{-8} x-1.904 \times 10^{-4}$ \\
Accuracy (recovery of gallic acid) (\%) & $90-110$ \\
Precision (CV) (\%) & 1.65 \\
Interday (\%) & 1.4 \\
Intraday (\%) & 1.6 \\
LOD (ng) & 38.3 \\
LOQ (ng) & 116.1 \\
Specificity & Specific \\
\hline
\end{tabular}

CV: Coefficient of variation; LOD: Limit of detection; LOQ: Limit of quantification

\section{Financial support and sponsorship}

Nil.

\section{Conflicts of interest}

There are no conflicts of interest.

\section{REFERENCES}

1. Prashar $Y$, Patel NJ. A review on Myrica nagi approach in recognizing the overall potential of the plant. Res J Life Sci Bioinform Pharm Chem Sci 2018;4:217-31.

2. Patel K, Rao Nj, Gajera V, Bhatt P, Patel K, Gandhi T. Anti-allergic Activity of Stem Bark of Myrica esculenta Buch.-Ham. (Myricaceae). J Young Pharm 2010;2:74-8.

3. Patel T, Dudhpejiya A, Sheath N. Anti inflammatory activity of Myrica nagi Linn. Bark. Anc Sci Life 2011;30:100-3.

4. Rana RK, Patel RK. Antioxidant activity of bark of Myrica nagi. Int J Pharm Sci Rev Res 2014;28:99-101.

5. Jain VK, Bindu J. Antihelmintic activity of ethanolic extract of bark of Myrica esculenta. Int J Pharm Sci Res 2010;1:129-31.1.

6. Saklani S, Kothiyal SC, Mishra A, Badoni P. Nutritional evaluation antimicrobial activity and phytochemical screening of wild edible fruit of Myrica nagi pulp. Int J Pharm Sci 2012;4:407-11

7. Khan Y, Sagrawat H, Upmanyu N, Siddique S. Anxiolytic properties of Myrica nagi bark extract. Pharm Biol 2008;11:757-61.

8. Alam A, Iqbal M, Saleem M, Ahmed S, Sultana S. Myrica nagi attenuates cumene hydroperoxide-induced cutaneous oxidative stress and toxicity in Swiss albino mice. Pharmacol Toxicol 2000;86:209-14.

9. Nguyen XN, Phan VK, Chau VM, Bui HT, Nguyen XC, Vu KT, et al. A new monoterpenoid glycoside from Myrica esculenta and the inhibition of angiotensin I-converting enzyme. Chem Pharm Bull (Tokyo) 2010;58:1408-10.

10. Patel T, Rajshekar C, Parmar R. Mast cell stabilizing activity of Myrica nagi bark. J Pharmacogn Phytother 2011;3:114-7.
11. Middha SK, Usha T, Babu D, Misra AK, Lokesh P, Goyal AK. Evaluation of antioxidative, analgesic and anti-inflammatory activities of methanolic extract of Myrica nagi leaves-an animal model approach. Symbiosis 2016;70:179-84.

12. Swathi D, Prasad KV. Antioxidant and antiulcer potential of ethanolic extract of bark of Myrica esculenta in pyloric ligation ulcer model. Int J Pharm Sci 2015;7:195-8.

13. Rawat S, Kumar N, Kothyal P. Evaluate the antidiabetic activity of Myrica esculenta leaves in streptozotocin-induced diabetes in rat. Int J Univers Pharm Bio Sci 2013;2:510-25

14. Samundeeswari C, Rajadurai M, Periasami R, Kanchana G. Hepatoprotective effect of Herbitars A polyherbal against $\mathrm{CCl} 4$ induced hepatotoxicity in rats. J Pharm Res 2011;4:676-9.

15. Nainwal P, Kalra K. Study on the wound activity potential on the aqueous extract of the bark of Myrica esculenta Buch. and Ham. Int J Pharm Clin Res 2009;1:85-7.

16. Mirghani ME, Liyana $Y$, Parveen J. Bioactivity analysis of lemongrass (Cymbopogan citratus) essential oil. Int Food Res J 2012;19:569-75.

17. Nile SH, Park SW. HPTLC densitometry method for simultaneous determination of flavonoids in selected medicinal plants. Front Life Sci 2015;8:97-103.

18. Lade BD, Patil AS, Paikrao HM, Kale AS, Hire KK. A comprehensive working principles and applications of thin layer chromatography. Res $\mathrm{J}$ Pharm Biol Chem Sci 2014;5:486-503.

19. Shivatare RS, Nagore DH, Nipanikar SU. "HPTLC" an important tool in standardization of herbal medical product: A review. Int J Sci Innov Res 2013;2:1086-96

20. Zhang $A$, Sun $H$, Wang $X$. Mass spectrometry-driven drug discovery for development of herbal medicine. Mass Spectrom Rev 2018;37:307-20.

21. Brain KR, Turner TD. Practical Evaluation of Phytopharmaceuticals. $1^{\text {st }}$ ed. Bristol: Wright-Scientechnica; 1975. p. 144.

22. Evans WC, Evans D, Trease GE. Trease and Evans Pharmacognosy. $16^{\text {th }}$ ed. New York: Saunders/Elsevier; 2009. p. 119-59.

23. Stahl E. Thin-Layer Chromatography: A Laboratory Handbook. Heidelberg: Springer International; 1969.

24. Wagner HC, Bladt S. Plant Drug Analysis. $2^{\text {nd }}$ ed. New Delhi: Thomson Press, Springer-Verlag Berlin Heidelberg; 1996.

25. Harborne JB. Phytochemical Methods. $3^{\text {rd }}$ ed. London: Chapman and Hall; 1973.

26. ICH. ICH Harmonised Tripartite Guideline. Validation of Analytical Procedures: Text and Methodology. International Conference on Harmonization of Technical Requirements for registrations of Pharmaceuticals for Human Use. Geneva, Switzerland: $\mathrm{ICH} ; 2005$. p. 1-13.

27. United States Pharmacopoeia. United States Pharmacopeia Convention, NF 26. Asian Edition. $31^{\text {st }}$ ed. Rockville, Md., United States; 2008. p. 1225

28. Patel K, Patel V, Patel K, Gandhi T. Validated HPTLC method for quantification of myricetin in the stem bark of Myrica esculenta Buch Ex D. J Planar Chromat 2010;23:326-31.

29. Harborne JB, Williams CA. Advances in flavonoid research since 1992 Phytochemistry 2000;55:481-504.

30. Sood P, Shri R. A review on ethnomedicinal phytochemical and pharmacological aspects of Myrica esculenta. Indian J Pharm Sci 2018;80:2-13.

31. Badhani B, Sharma N, Kakkar R. Gallic acid: A versatile antioxidant with promising therapeutic and industrial applications. RSC Adv 2015;5:27540-57.

32. Maji JK, Patel M, Patel S, Butani S, Mehta P. High-performance thin layer chromatography method development and validation for simultaneous determination of phenolic acids in selected Indian Bamboo species. Pharm Methods 2019;10:21-6.

33. Attimarad M, Ahmed KK, Aldhubaib BE, Harsha S. High-performance thin layer chromatography: A powerful analytical technique in pharmaceutical drug discovery. Pharm Methods 2011;2:71-5. 